Article

\title{
Improvement of the Interfacial Fatigue Strength and Milling Behavior of Diamond Coated Tools via Appropriate Annealing
}

\author{
Georgios Skordaris ${ }^{1, *(D)}$, Tilemachos Kotsanis ${ }^{1}$, Apostolos Boumpakis ${ }^{1}$ and Fani Stergioudi ${ }^{2}$ \\ 1 Laboratory for Machine Tools and Manufacturing Engineering, Mechanical Engineering Department, \\ Aristotle University of Thessaloniki, 54124 Thessaloniki, Greece; tilemahoskotsanis@gmail.com (T.K.); \\ ampoumpak@auth.gr (A.B.) \\ 2 Physical Metallurgy Laboratory, Mechanical Engineering Department, Aristotle University of Thessaloniki, \\ 54124 Thessaloniki, Greece; fstergio@auth.gr \\ * Correspondence: skordaris@meng.auth.gr; Tel.: +30-2310-996-027
}

Received: 29 July 2020; Accepted: 22 August 2020; Published: 25 August 2020

check for updates

\begin{abstract}
This article deals with the potential to reduce the amount of the residual stresses in the diamond films on cemented carbide inserts for improving their effective interfacial fatigue strength and thus their wear resistance. In this context, nano-crystalline diamond coatings (NCD) were deposited on cemented carbide inserts. A portion of these coated tools were annealed in vacuum for decreasing the amount of residual stresses in the film structure. The annealing temperature was appropriately selected for keeping the substrate strength properties invariable after the coating annealing. Inclined impact tests at ambient temperature on the untreated and heat-treated diamond coated tools were conducted for evaluating their effective interfacial fatigue strength. Depending upon the impact load, after a certain number of impacts, damages in the film-substrate interface develop, resulting in coating detachment and lifting. Via appropriate FEM (Finite Element Method)-evaluation of the impact imprints, the residual stresses in the diamond film structure were determined. Milling experiments were conducted for evaluating the cutting performance of the coated tools using aluminum foam as workpiece material. A correlation between the interfacial fatigue strength of diamond coatings and their residual stresses affected by annealings contributed to the explanation of the attained cutting results.
\end{abstract}

Keywords: diamond coatings; residual stresses; interfacial fatigue strength; annealing; milling

\section{Introduction}

Diamond coatings deposited on cemented carbide tools are widely used in machining of non-ferrous materials like aluminum alloys, composite and so forth [1-5]. A key issue for ensuring a sufficient diamond coated tool life, especially in milling, is the fatigue strength of diamond coating-substrate interface [6-8]. For enhancing the diamond film bonding on its substrate and thus the film adhesion, selective chemical Co-etching is carried out on hard metal tools for decreasing superficially the non-adhesive cobalt [1,4]. Moreover, the application of interlayer materials was introduced as an effective technology for enhancing the film adhesion and nucleation densities of diamond coatings on various substrates [4,6,9-11].

In the present paper, the potential to change the amount of residual stresses in the diamond film structure via appropriate heat treatment, thus increasing the effective interfacial fatigue strength as well as the wear resistance of diamond coated tools in milling was investigated. Nano-crystalline diamond (NCD) coatings deposited on cemented carbide tools are characterized by high residual stresses. The high level of residual stresses in the diamond film structure are attributed to epitaxial 
crystal differences and thermal expansion coefficients mismatch of the diamond coating and its cemented-carbide substrate [12-14]. In this context, annealings were carried out using the NCD coated tools for attaining a relaxation of the residual stresses [15]. Moreover, Raman spectra were applied to study the crystallinity of the as deposited as well as annealed diamond coatings $[5,16]$. Nano-indentations coupled with appropriate finite element method (FEM)-simulations were applied for characterizing the substrate mechanical properties at ambient and at annealing temperature [17]. As a result, potential change of the wear behavior of diamond coated tools due to annealing can be attributed only to the relaxation of the film residual stresses.

The effective interfacial fatigue strength of the as deposited and heat-treated NCD coated tools was investigated by conducting inclined impact tests at ambient temperature and at various loads and number of impacts. Under certain impact conditions, the conduct of the inclined impact test results in the development of interfacial fatigue micro-cracks and damages. As a consequence, a release of the residual stresses in the diamond film structure takes place leading to bulge formation [7]. Via appropriate FEM-evaluation of the impact imprints, the residual stresses in the examined diamond coatings were calculated [18]. Moreover, milling experiments were carried out for evaluating the cutting performance of the prepared NCD coated inserts using aluminum foam as workpiece material. Based on the achieved results, optimum annealing conditions can be determined for improving the wear resistance of the NCD coated tools in milling.

\section{Experimental and Computational Details}

Nano-composite diamond coatings (NCD) were deposited on cemented carbide inserts of HW-K05 SPGN 120308 specifications via hot filament method using a CC800/9Dia Cemecon coating machine (Würselen, Germany). The applied temperature of the filament and substrate during the deposition process were $2000{ }^{\circ} \mathrm{C}$ and $900{ }^{\circ} \mathrm{C}$, respectively. Moreover, a cooling process took place after the coating deposition lasting for $9 \mathrm{~h}$. The coating thickness amounts to approximately $5 \mu \mathrm{m}$. For achieving a sufficient film adhesion, cobalt-etching procedures were conducted prior to the coating deposition [6]. A portion of the produced diamond inserts was annealed in vacuum for a duration of $3 \mathrm{~h}$ and $10 \mathrm{~h}$. The annealing temperature was set equal to $400^{\circ} \mathrm{C}$. In this way, three groups of diamond coated inserts were created possessing different annealing durations.

For characterizing the crystallinity of the as deposited and annealed at different conditions diamond coatings, Raman spectroscopy was carried out using a LabRAM HR spectrometer (HORIBA FRANCE SAS). The recorded spectra are presented in Figure 1. The as deposited as well as the annealed diamond coatings appear a narrow peak at $1332 \mathrm{~cm}^{-1}$. This peak is associated with a diamond coating characterized by high crystalline quality [16]. Moreover, the captured spectra for all investigated coating cases are similar. Thus, it can be stated that the effect of the temperature up to $400{ }^{\circ} \mathrm{C}$ on the crystallinity of diamond coatings is negligible.

For evaluating the substrate strength properties before and after annealing at $400{ }^{\circ} \mathrm{C}$, nanoindentations were conducted by a FISCHERSCOPE H100 device (Helmut Fischer GmbH, Sindelfingen, Germany) [17]. The fatigue strength of the coating-substrate interface was assessed by inclined impact tests at various loads and cycles using an impact tester designed and manufactured by the Laboratory for Machine Tools and Manufacturing Engineering of the Aristotle University of Thessaloniki in conjunction with the company Impact-BZ [19]. The load inclination angle was $15^{\circ}$ and the ball diameter was $5 \mathrm{~mm}$ (see Figure 2a). The applied time-dependent force signal is shown in Figure $2 b$. The 3D-measuement facilities of the confocal microscope $\mu$ SURF of NANOFOCUS AG (Oberhausen, Germany) were used for evaluating the impact imprints. The milling experiments were conducted without coolant or lubricant for attaining a more intense wear evolution. The workpiece material was an aluminum foam. Based on standard metallographic techniques, the various hard phases of the workpiece material were detected and described in Figure 2c. It has to be pointed out that the coated cutting edge is loaded by high dynamic loads during milling owing to the structure of workpiece material. 


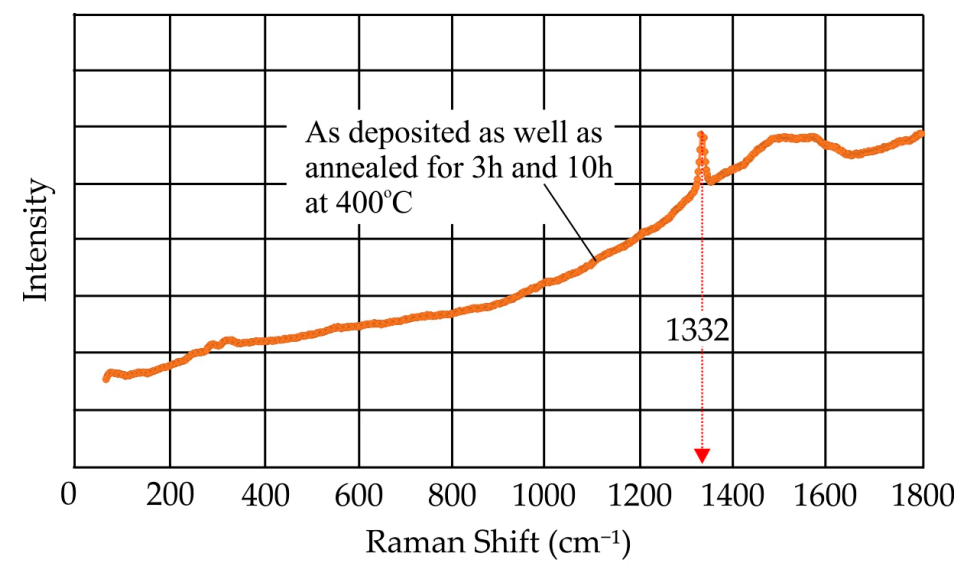

NCD diamond coating, $\mathrm{t} \approx 5 \mu \mathrm{m}$, substrate: HW-K05

Figure 1. Raman spectra of the as deposited as well as the annealed at different conditions diamond coatings for investigating their crystallinity.
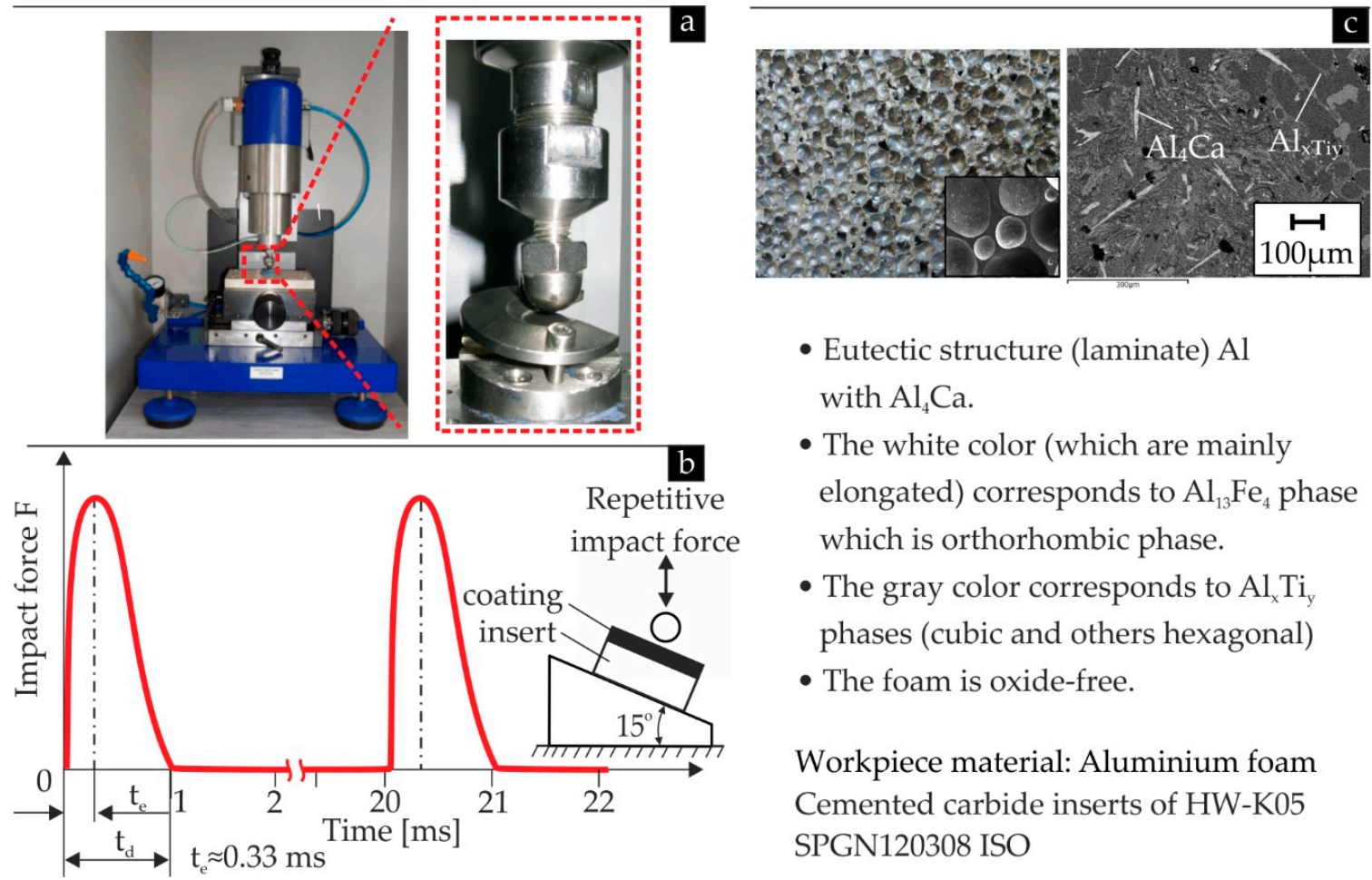

- Eutectic structure (laminate) $\mathrm{Al}$ with $\mathrm{Al}_{4} \mathrm{Ca}$.

- The white color (which are mainly elongated) corresponds to $\mathrm{Al}_{13} \mathrm{Fe}_{4}$ phase which is orthorhombic phase.

- The gray color corresponds to $\mathrm{Al}_{\mathrm{x}} \mathrm{Ti}_{\mathrm{y}}$ phases (cubic and others hexagonal)

- The foam is oxide-free.

Workpiece material: Aluminium foam Cemented carbide inserts of HW-K05 SPGN120308 ISO

Figure 2. (a) The device for conducting inclined impact tests; (b) the applied force signals during the inclined impact test; (c) characteristic micro-graphs of the aluminum foam used in milling experiments.

An axisymmetric FEM-model was employed using ANSYS 18 software for determining the thermal residual stresses in the diamond film structure, as shown in Figure $3 \mathrm{a}$ and described analytically in Reference [18]. The applied FEM-algorithm (FEM-TRS algorithm) enables the calculation of thermal compressive stresses in the NCD structure during cooling from the deposition temperature to the ambient one taking into account the different thermal expansion coefficients of the diamond coating and the cemented carbide substrate.

Moreover, the maximum residual stresses in the diamond coating structures before and after annealing were determined by an appropriate FEM-model using ANSYS software, as shown in Figure $3 \mathrm{~b}$ and described analytically in Reference [18]. By using the experimental data of the diameter of detached film region in each examined coating case after inclined impact test, the goal of the applied FEM-DRS (Finite Element Method-Distributed Resource Schedule) algorithm is to describe 
the geometry of the formed film bulges [18]. In this context, a pressure is applied to the FEM-model elements until the deformation height at the most elevated central bulge region to be equal with the relevant measured film bulge maximum height. Thus, the overall compressive residual stresses in the diamond film structure can be determined.

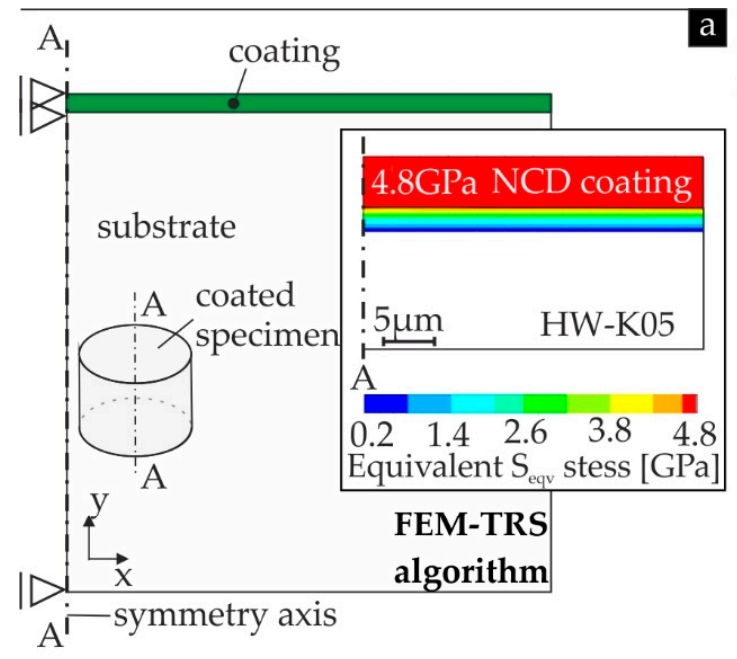

Thermal expansion coefficient $\alpha$ substrate: $\mathrm{HW} / \mathrm{K} 05 \alpha=5.2 \times 10^{-6} /{ }^{\circ} \mathrm{C}$ coating: $\mathrm{NCD} \alpha=1.1 \times 10^{-6} /{ }^{\circ} \mathrm{C}$

NCD coating deposition temperature: $900^{\circ} \mathrm{C}$ cooling temperature: $20^{\circ} \mathrm{C}$

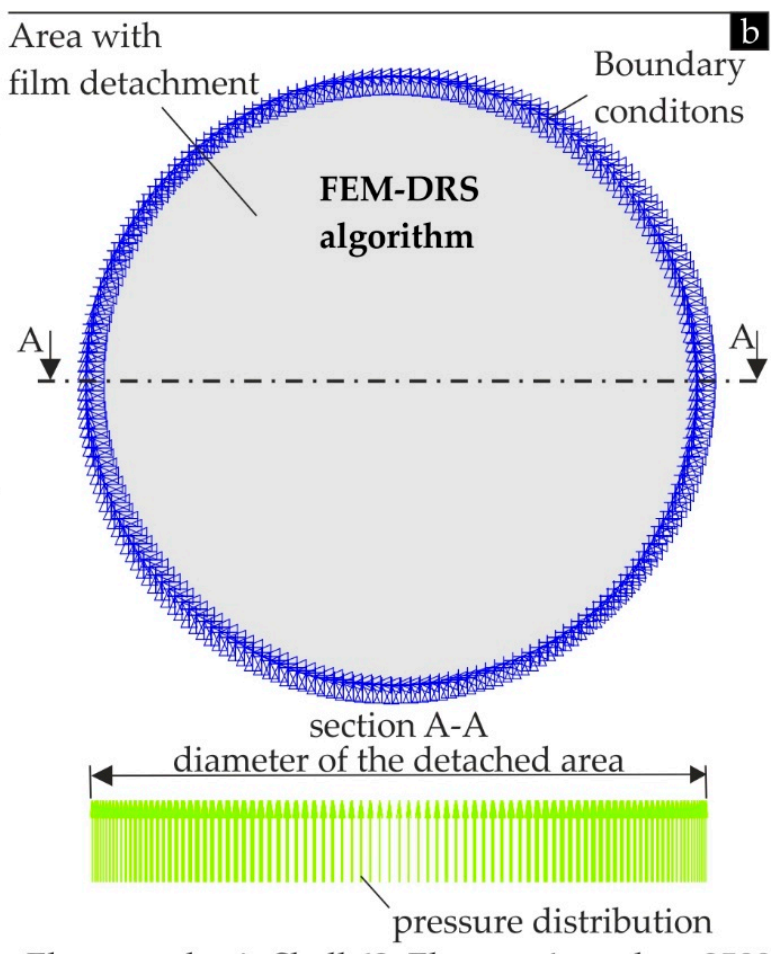

Element: elastic Shell 63, Elements' number $\approx 2500$

Elasticity modulus $=1100 \mathrm{GPa}$, Poisson's ratio $=0.07$

Figure 3. The applied finite element method (FEM) model for calculating (a) the thermal residual stresses and (b) the overall residual stresses in film structure after the diamond coating deposition and its annealing.

\section{Results and Discussion}

\subsection{Mechanical Properties of Cemented Carbide Substrates before and after Annealing}

Since the goal of this work was to improve the effective interfacial fatigue strength of diamond coated tools and thus their wear behavior in milling via appropriate annealing, it was necessary to ensure that the effect of the applied annealing process on substrate mechanical properties is negligible. In this way, uncoated HW-K05 cemented carbide substrates were annealed in vacuum at a temperature of $400^{\circ} \mathrm{C}$ corresponding to the related one during the annealing of the diamond coated tools. Herewith, the effect of the annealing temperature on the substrate strength properties was recorded by conducting nanoindentations at a maximum indentation load of $50 \mathrm{mN}$. In order the effect of the specimen roughness on the results accuracy to be nullified, 30 measurements per nanoindentation were conducted [17]. The related load-displacement diagrams for both examined cases are shown in Figure 4a. According to the obtained results, the load-displacement curve of cemented carbide subjected to an annealing at $400{ }^{\circ} \mathrm{C}$ is similar to the corresponding one of an untreated substrate. By appropriate FEM-evaluation of the nanoindentation results, the mechanical characteristics for both cemented carbide inserts are shown in Figure $4 b$ [17]. Based on the attained results, it can be stated that potential change of the wear behavior of diamond coated tools via annealing can be attributed only to the relaxation of the film residual stresses and not to substrate effects. 


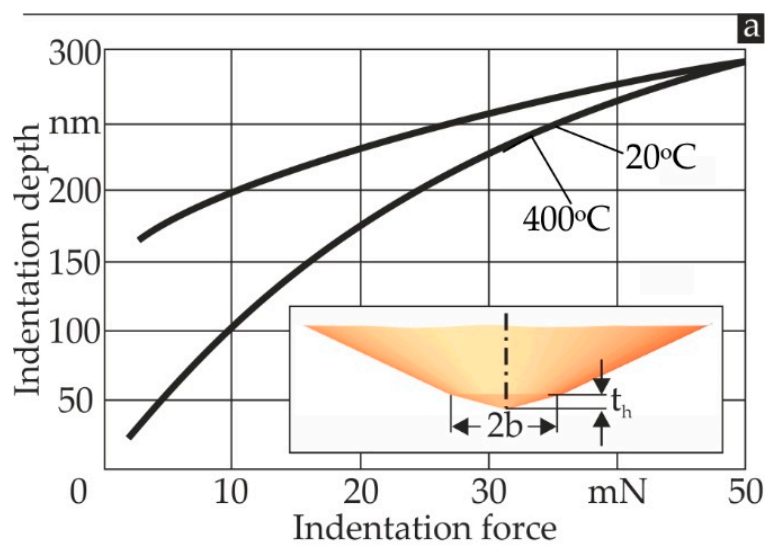

Berkovich indenter, tip geometry: $t_{h} / b=2 / 89 \mathrm{~nm}$ NCD coating/ HW-K05 substrate, $\mathrm{t} \approx 5 \mu \mathrm{m}$

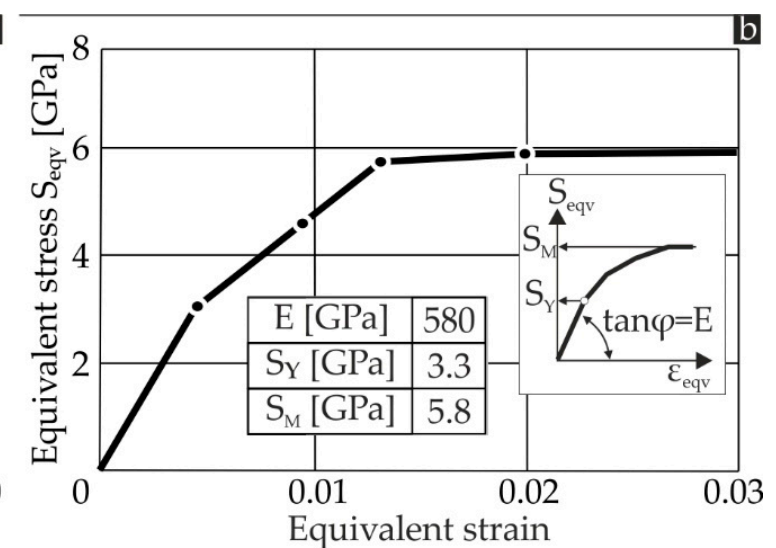

Figure 4. (a) Nanoindentation load-displacement curves; (b) Calculated stress-strain curves of HW-K05 cemented carbide inserts before and after annealing at $400{ }^{\circ} \mathrm{C}$.

\subsection{Residual Stresses in NCD Coatings before and after Their Annealings}

Annealings were conducted on the diamond coated tools in vacuum for $3 \mathrm{~h}$ and $10 \mathrm{~h}$ at a temperature of $400{ }^{\circ} \mathrm{C}$. Taking into account the dominant effect of the strength properties of the cemented carbide substrates on the capability of coated tools to withstand the dynamic loads in interrupted cutting processes, the annealing temperature of $400^{\circ} \mathrm{C}$ was intentionally selected. At the temperature of $400{ }^{\circ} \mathrm{C}$, the $\mathrm{HW}-\mathrm{K} 05$ substrate strength properties remain invariable, as also described in the Section 3.1 [20]. In the first step of the conducted investigations, it was necessary to determine the developed residual stresses in the film structure before and after annealing. Based on an appropriate axisymmetric FEM-model described in Figure 3a (FEM-TRS algorithm), the developed thermal stresses due to the different thermal expansion coefficients of the diamond coating and cemented carbide substrate after cooling from the deposition temperature to the ambient one were calculated and amount to approximately $4.8 \mathrm{GPa}$. These compressive stresses remain constant in all investigated annealing cases. The magnitude of the thermal residual stresses depends only on the operational temperature of the diamond coated tools and the coating deposition temperature. In all cases, the inclined impact tests for evaluating the interfacial fatigue strength of diamond coated tools were conducted at ambient temperature. Moreover, by using a further FEM-model described in Figure 3b (FEM-DRS algorithm), the overall amount of residual stresses in the film structure were calculated. This FEM-model, as already described in Section 2, simulates the film lifting due to the fatigue failure of its interface at ambient temperature and the residual stress release after the conduct of inclined impact test considering the diameter and height of the formed bulges. The diameter of each detached region after the inclined impact test corresponds to a certain film bulge height depending on the amount of the residual stresses in the diamond coating structure [21].

A characteristic example illustrating the applied procedure for determining the residual stresses in the as deposited diamond coating structure is shown in Figure 5. The dimensions of the formed bulge after inclined impact test at certain conditions (diameter and height) are used as input parameters in the FEM-DRS algorithm for calculating the overall compressive residual stress in the diamond film structure (see Figure 5a). The overall principal stresses in $\sigma_{1}$ and $\sigma_{2}$ directions are equal and amount to approximately 10.2 GPa (see Figure $5 \mathrm{~b}$ ). Moreover, the corresponding compressive thermal residual stresses of the diamond coating in the same principal directions are calculated using the FEM-TRS algorithm (see Figure 5c). By subtracting the thermal residual stresses from the overall residual stresses, the remaining residual stresses in the diamond film structure, characterized as structural, were calculated (see Figure 5d) [7]. These stresses are generated during the film deposition and can be varied after the annealing process. 

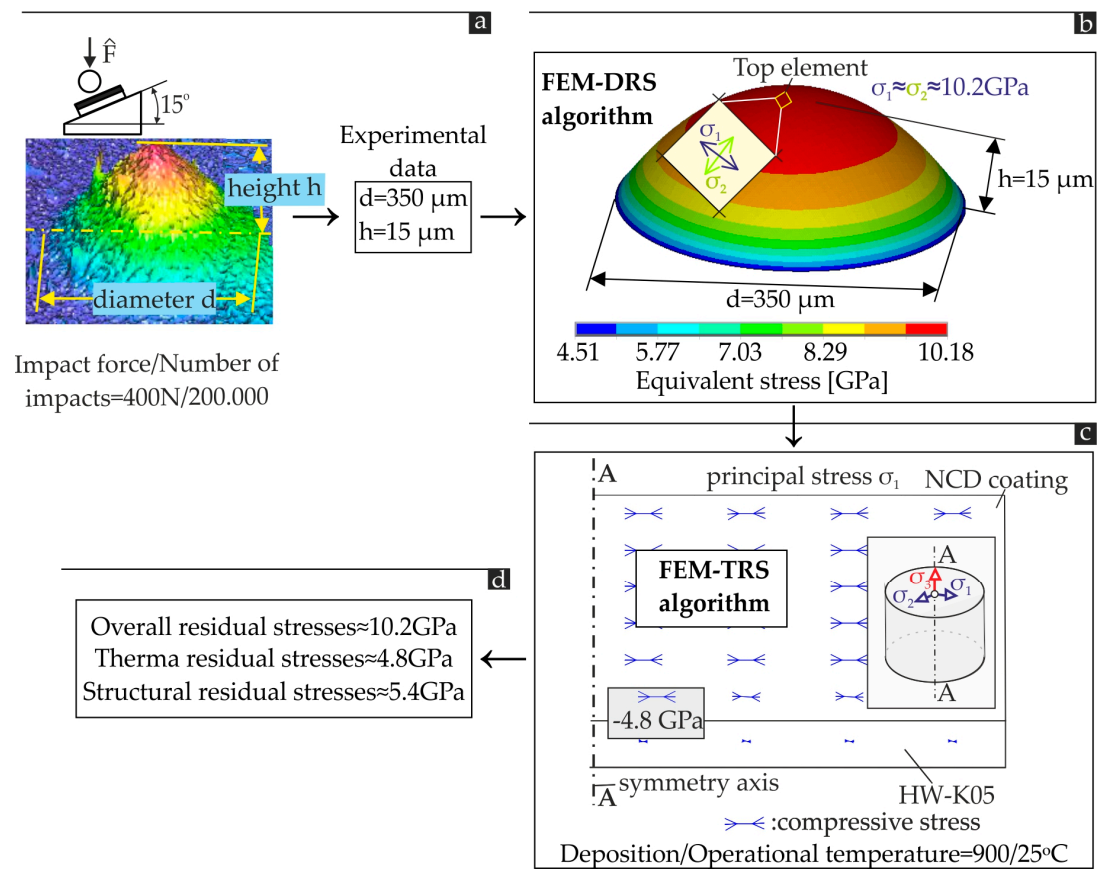

Figure 5. (a) Determination of the input parameters (diameter and height of the formed bugle) in the FEM-DRS algorithm; (b) calculation of the overall compressive stresses in the diamond film structure via FEM-DRS algorithm; (c) calculation of the thermal compressive stresses in the diamond film structure via FEM-TRS algorithm; (d) determination of the structural stresses in the diamond film structure.

Characteristic impact imprints after various number of impacts and loads at ambient temperature of the untreated as well as of the annealed diamond coated tools are shown in Figure 6. Taking into account the mechanical properties and the dimensions (diameter and height) of the formed bulges in each case as an input parameter in the FEM-model shown in Figure 3b (FEM-DRS algorithm), the overall residual stresses were calculated. According to the attained results, an increase of the annealing duration results in a significant reduction of the structural residual stresses. More specifically, after an annealing duration of $10 \mathrm{~h}$, the structural residual are almost negligible and only thermal stresses exist in the film structure.

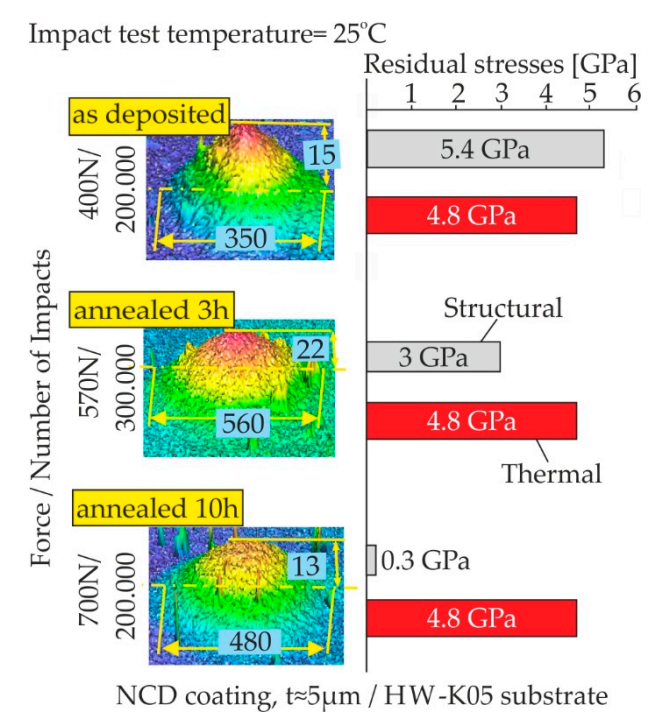

Figure 6. FEM-calculated thermal and structural stresses in the investigated coating cases based on the dimensions of the developed bulges after inclined impact tests and appropriate evaluation by using FEM-DRS and FEM-TRS algorithms. 


\subsection{Evaluation of the Interfacial Fatigue Strength of Diamond Coated Tools before and after Their Annealings}

Inclined impact tests were conducted on the as deposited and annealed coated tools at various loads and number of impacts for evaluating their interfacial fatigue strength. During the conduct of the inclined impact test, shear stresses are developed in the diamond film-substrate interface. If the developed interface stresses lead to loads in the film substrate interface, which exceed the interfacial toughness of the film, an interface fatigue failure occurs. As a consequence, the high compressive residual stresses in the NCD structure are released hiking up the detached area at certain maximum height. The interfacial toughness of the diamond coatings depends strongly on the level of residual stresses in the film structure.

In Figure 7, characteristic topomorphies of the developed imprints on the untreated NCD coated insert at an impact load of $350 \mathrm{~N}$ after 100,000 as well as 300,000 and 400,000 impacts at ambient temperature are shown. After 100,000, there is no any sign of damage in the coating surface. An interface failure takes place after 300,000 impacts resulting to the bulge formation with a height of about $15 \mu \mathrm{m}$. The bugle is totally damaged and removed after only a further 100,000 impacts. Related topomorphies of impact imprints on the annealed coated inserts after $3 \mathrm{~h}$ and $10 \mathrm{~h}$ are illustrated at a load of $600 \mathrm{~N}$ and $650 \mathrm{~N}$ in Figures 8 and 9, respectively. The developed mechanism for diamond coating damage under the application of repetitive dynamic loads is similar including the coating detachment and its removal.

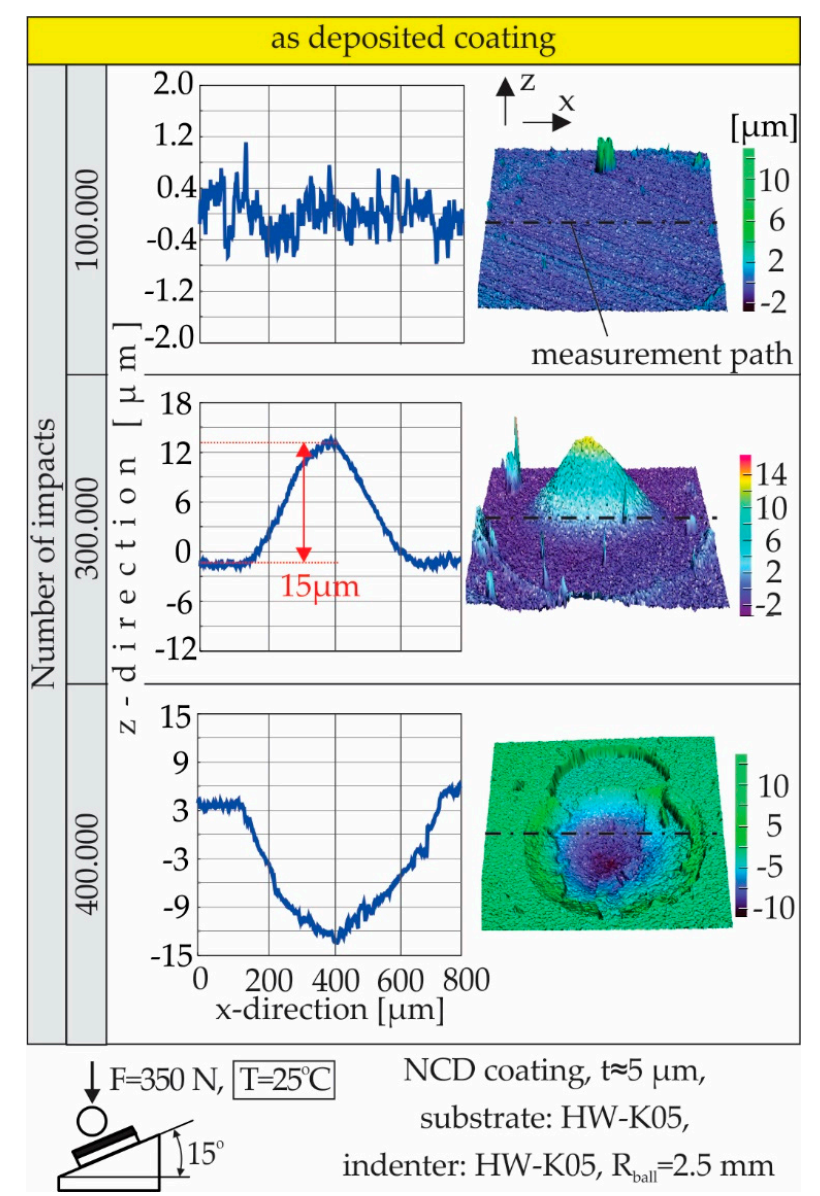

Figure 7. Impact test results on the as deposited nano-crystalline diamond (NCD) coated inserts at an impact load of $350 \mathrm{~N}$ after various number of impacts. 


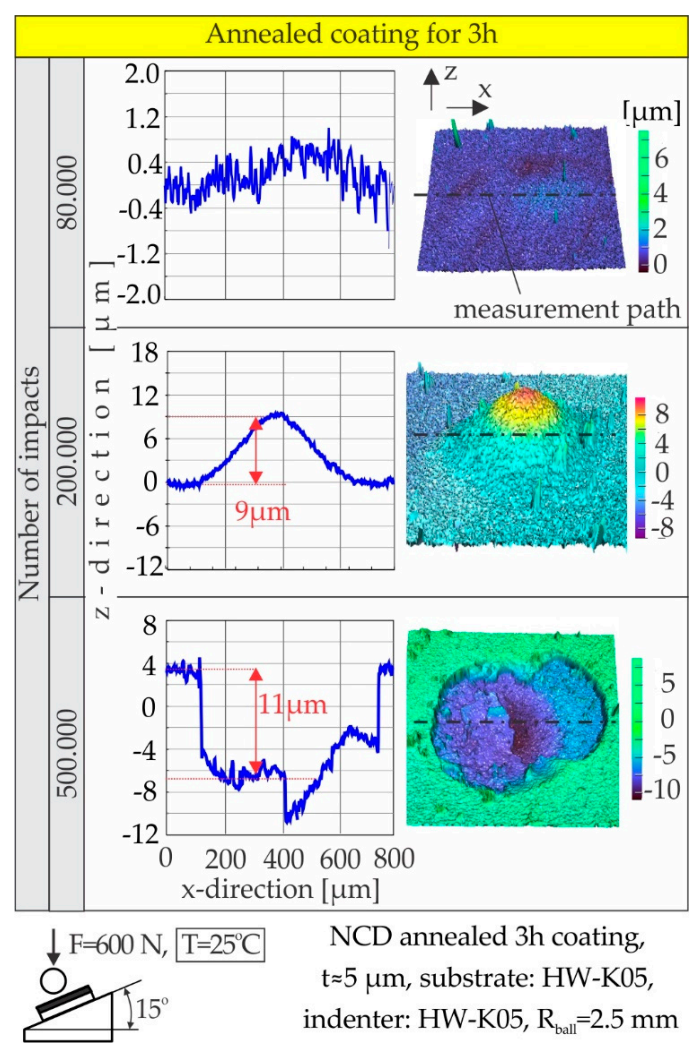

Figure 8. Impact test results on the annealed NCD coated inserts for $3 \mathrm{~h}$ at an impact load of $600 \mathrm{~N}$ after various number of impacts.

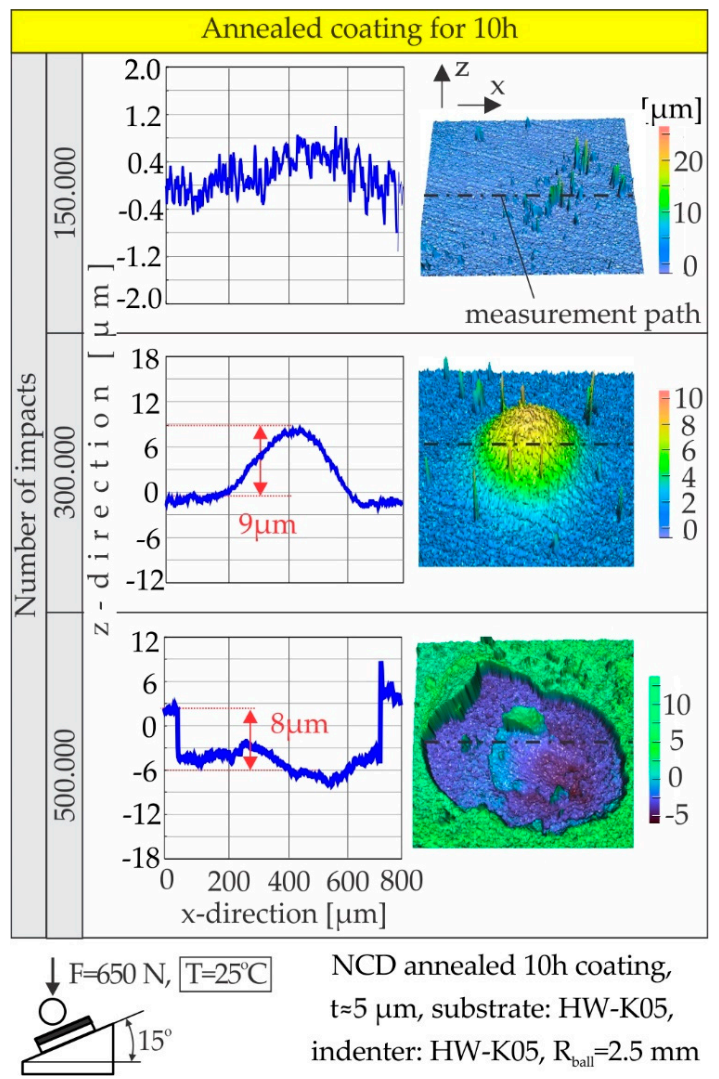

Figure 9. Impact test results on the annealed NCD coated inserts for $10 \mathrm{~h}$ at an impact load of $650 \mathrm{~N}$ after various number of impacts. 
An overview concerning the occurring topomorphy of the as-deposited and annealed diamond coated tools after the conduct of the inclined impact tests at various loads and the number of impacts is shown in Figure 10a. All the impact tests were conducted at ambient temperature. After a certain combination of the impact load and number of impacts, bulges are formed. The experimentally detected maximum forces for avoiding the fatigue failure of the diamond coating-substrate interface after $10^{6}$ impacts for the untreated as well as the annealed diamond coated tools after $3 \mathrm{~h}$ and $10 \mathrm{~h}$ amount to approximately $300 \mathrm{~N}, 525 \mathrm{~N}$ and $625 \mathrm{~N}$ (see Figure 10b). An impressive increase of threshold load for interfacial fatigue damage initiation after $10^{6}$ impacts occurs when the structural stresses in the film structure are nullified due to the applied annealing process for $10 \mathrm{~h}$.
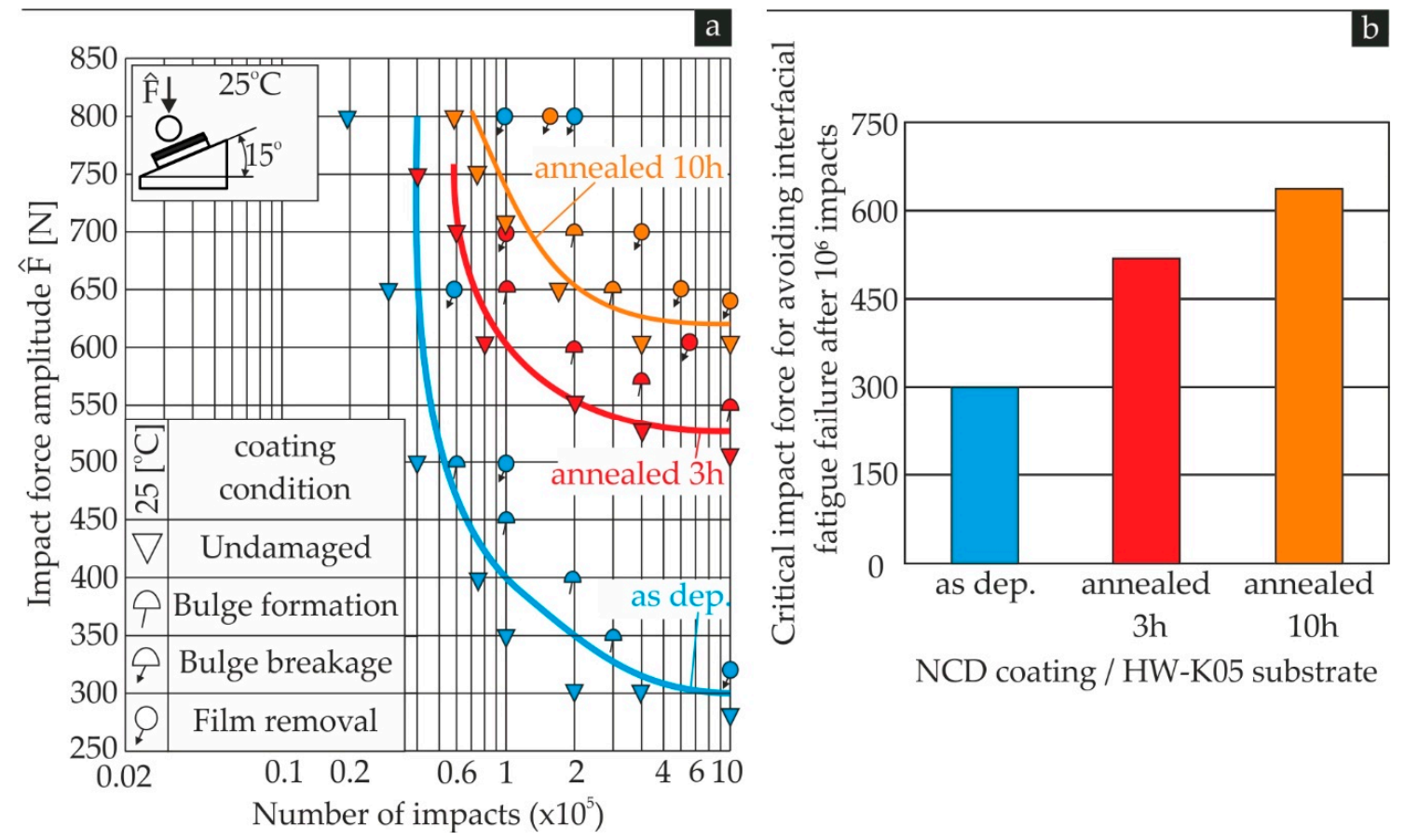

Figure 10. (a) NCD coating status after inclined impact tests at different combinations of impact load and number of impacts; (b) critical impact forces for avoiding interfacial damage after $10^{6}$ impacts in the examined coating cases.

\subsection{Explanation of the Attained Impact Test Results}

For explaining the effect of the residual stresses of the NCD coating on its effective interfacial fatigue strength, the FEM-DRS algorithm was used (see Section 2). More specifically, two characteristic cases of NCD coatings were considered possessing overall residual stresses equal to approximately 10.2 GPa (as deposited case) and 5.1 GPa (annealed for $10 \mathrm{~h}$ ) (see Figure 11a). In order to achieve a bulge height of $1 \mu \mathrm{m}$ in both examined cases, the detached film region due to the interfacial fatigue failure is different. In the case of an NCD coating with residual stresses equal to approximately $10.2 \mathrm{GPa}$, the detached film area is associated with a diameter of only $60 \mu \mathrm{m}$, as shown in Figure 11b. However, a decrease of the residual stresses in the diamond film structure results in a significant augmentation of the detached film area for attaining the same coating lifting (see Figure 11b). Based on these results, it can be stated that the high level of residual stresses in NCD diamond coating triggers a coating lifting and removal when a fatigue damage occurs even in a restricted region in the coating-substrate interface, thus worsening the coating fatigue strength. 

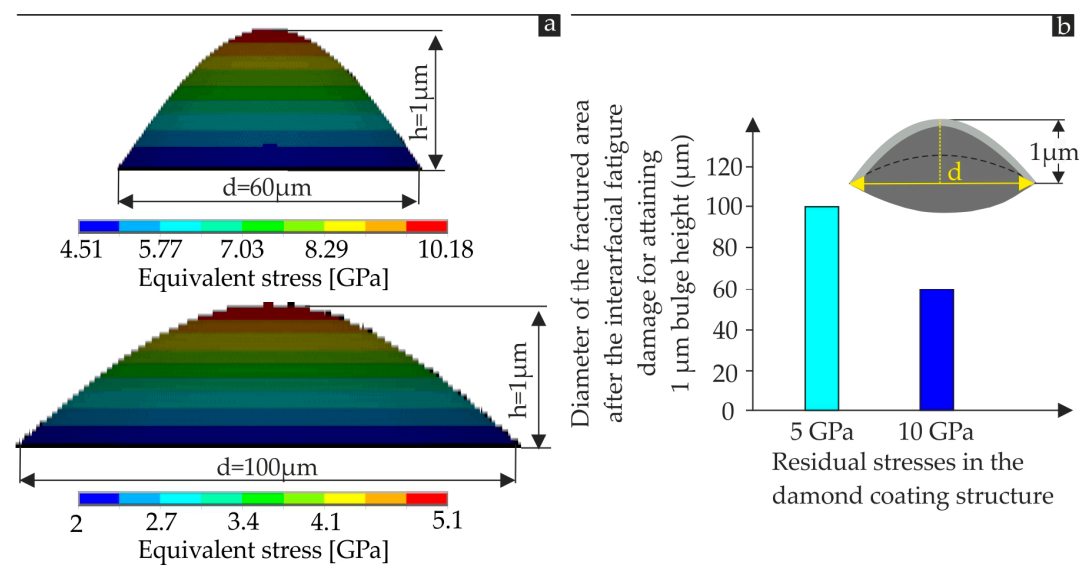

Figure 11. (a) Characteristic diamond coating cases for investigating the effect of the amount of their residual stresses on the occurring dimensions of the film bulges; $(\mathbf{b})$ the occurring diameter of the fractured area of the investigated coating cases in order to attain $1 \mu \mathrm{m}$ bulge height.

\subsection{Wear Behavior of the Untreated and Annealed Diamond Coated Tools in Milling}

The cutting performance of the untreated and annealed diamond coated tools was investigated in dry milling. In the way, the evolution of the wear was accelerated. Moreover, due to the structure of the aluminum foam used as workpiece material and the existence of especially hard phases, as already described in Figure 2c, intense dynamic load are developed in the coated cutting edge. In this way, a key-issue for attaining a sufficient tool life in milling is the interfacial fatigue strength of the diamond coated tool. After a prescribed number of successive cuts, the cutting insert wear was recorded. According to the cutting results shown in Figure 12a, in the case of the untreated coated tools, a flank wear width of $0.15 \mathrm{~mm}$ developed after only approximately 15,500 cuts. Moreover, the application of inserts annealed for $3 \mathrm{~h}$ at $400{ }^{\circ} \mathrm{C}$ enhances the coated tool life up to roughly 50,000 cuts. Coated inserts annealed for $10 \mathrm{~h}$ exhibit the best cutting performance reaching an impressive tool life of almost 78,000 cuts. Characteristic micro-graphs of the worn cutting edges in the examined annealing cases are shown in Figure 12b.
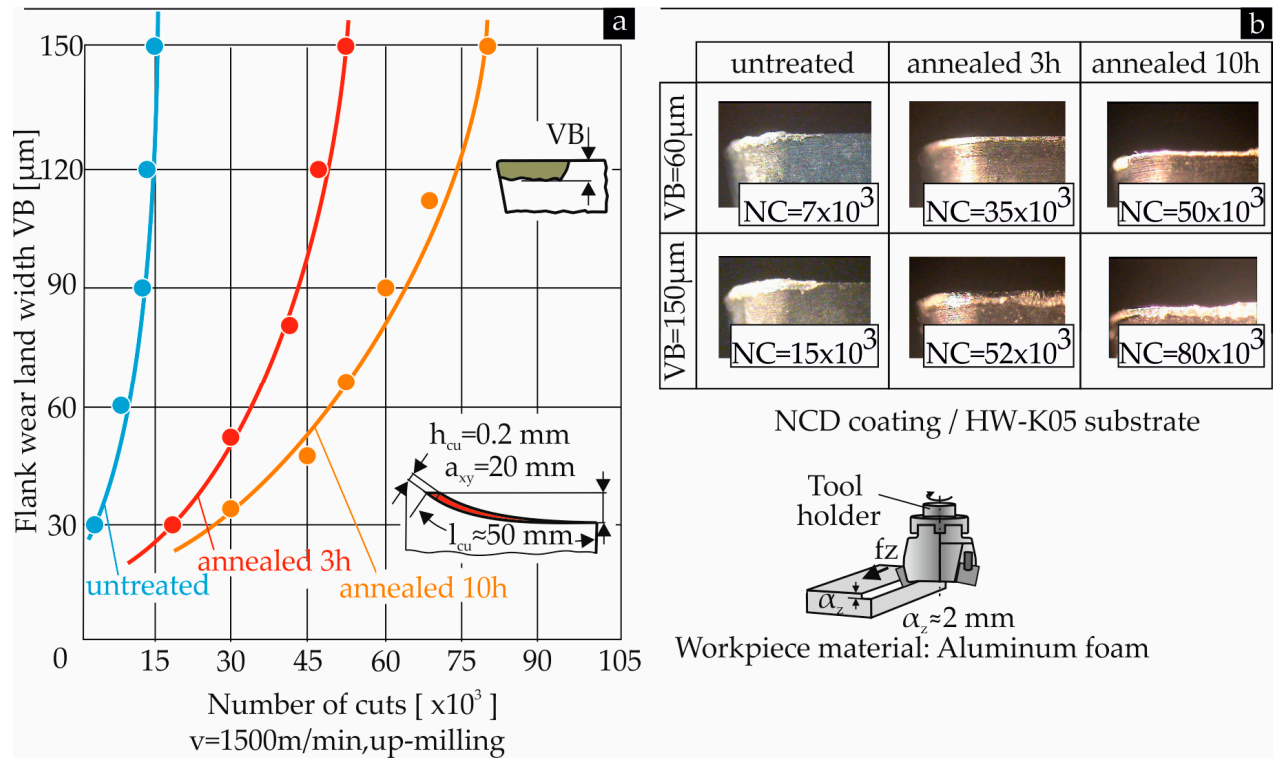

NCD coating / HW-K05 substrate

Tool

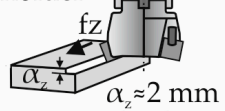

Workpiece material: Aluminum foam

Figure 12. (a) Flank wear development versus the number of cuts of the investigated diamond coated inserts; (b) characteristic micro-graphs of the worn cutting edges in the examined coated inserts. 


\subsection{Review of the Obtained Results}

A correlation among the diamond coating's residual stresses, the threshold impact load for interface fatigue endurance after $10^{6}$ impacts as well as the tool life up to a flank wear width of $0.15 \mathrm{~mm}$ of the untreated (see Figure 13a) and annealed (see Figure 13b,c) coated tools at various conditions is conducted for having an overview of the achieved results. It is obvious that a decrease of the structural residual stresses in the diamond film structure due to annealing leads to a significant augmentation of the critical load for the initiation of diamond coating-substrate interface damage. As a result, the capability of the diamond coated cutting edge to withstand the dynamic loads in milling is enhanced resulting to an impressive enhancement of the coated tool life. It has to be pointed out that a percentile increase of approximately $400 \%$ of the coated tool life is attained when the structural residual stresses are totally removed from the initial diamond coating state after annealing.
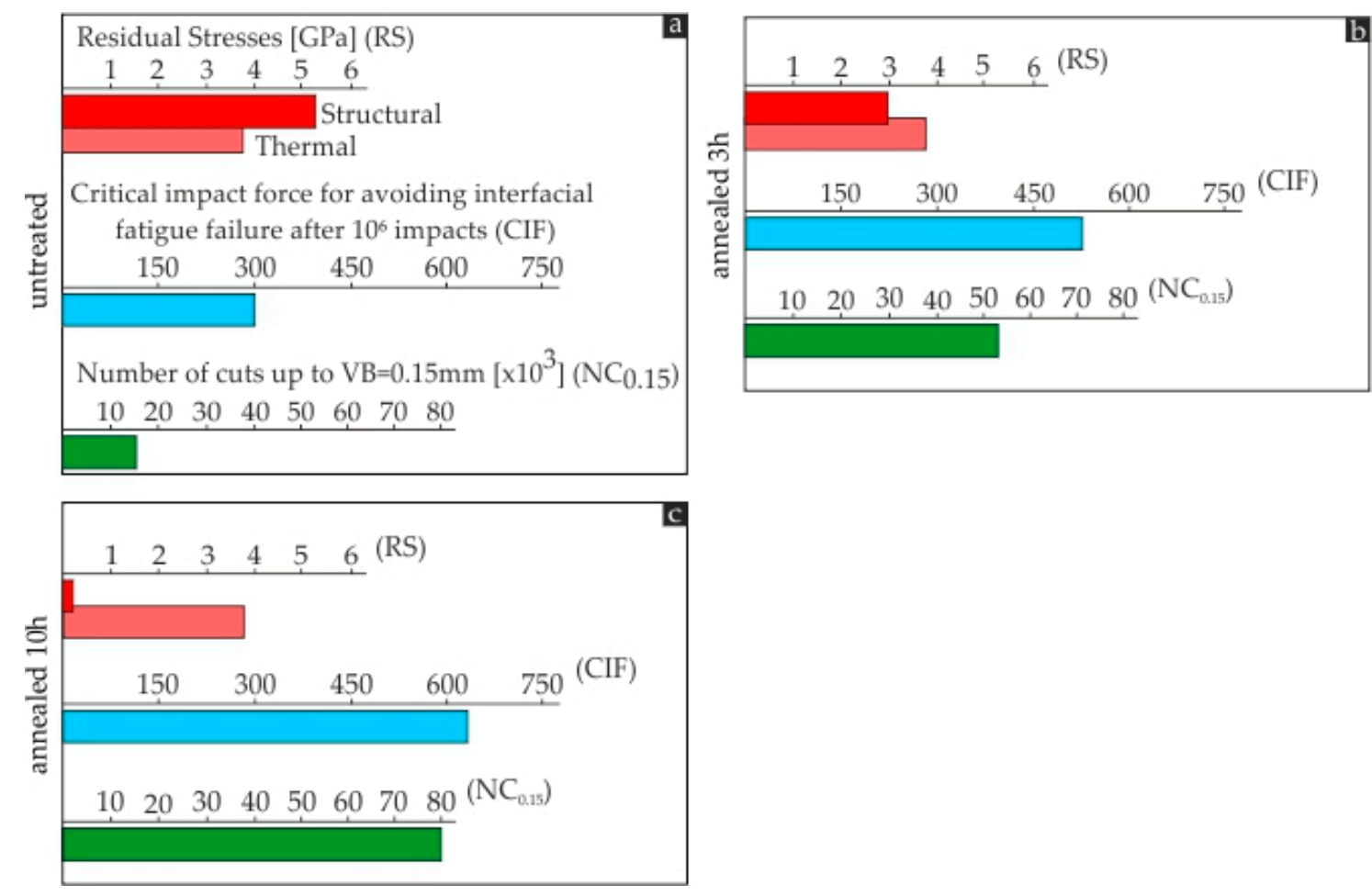

Figure 13. Correlation among NCD film residual stresses, interfacial fatigue strength as well as coated tool life in milling in the case of (a) an untreated coated tool; (b) an annealed one for $3 \mathrm{~h}$ at $400{ }^{\circ} \mathrm{C}$; and (c) an annealed one for $10 \mathrm{~h}$ at $400^{\circ} \mathrm{C}$.

\section{Conclusions}

In the frame of this work, the potential to improve the wear behavior in the milling of NCD coated cemented carbide inserts via appropriate annealing was investigated. The obtained results show that an impressive enhancement of the effective interfacial fatigue strength and milling performance of diamond coated tools can be achieved by decreasing the structural residual stresses in the diamond film structure. More specifically, when the structural residual stresses are nullified via an appropriate adjustment of the annealing duration and temperature, the coated tool life is approximately four times larger than the initial one and thus the number of the worn tool replacements decreases significantly in machining processes. In this way, the conduct of the annealing process on NCD coated tools using appropriate conditions is highly recommended for improving their cutting performance.

Author Contributions: Conceptualization, G.S., F.S., T.K., and A.B.; methodology, G.S., F.S., T.K., and A.B.; software, G.S., F.S., T.K., and A.B.; investigation, G.S., F.S., T.K., and A.B.; data curation, T.K. and A.B.; writing-original draft preparation, G.S., F.S., T.K., and A.B.; writing-review and editing, G.S., F.S., T.K., and A.B.; supervision, 
G.S. and F.S.; project administration, G.S. and F.S.; All authors have read and agreed to the published version of the manuscript.

Funding: This research is co-financed by Greece and the European Union (European Social Fund-ESF) through the Operational Programme "Human Resources Development, Education and Lifelong Learning 2014-2020" in the context of the project "Optimization of the cutting performance of nano- and micro-structured diamond coatings via appropriate thermal treatments" (MIS 5047906).

Conflicts of Interest: The authors declare no conflict of interest.

\section{References}

1. Haubner, R.; Kalss, W. Diamond deposition on hardmetal substrates-Comparison of substrate pre-treatments and industrial applications. Int. J. Refract. Met. Hard Mater. 2010, 28, 475-483. [CrossRef]

2. Ng, E.-G.; Szablewski, D.; Dumitrescu, M.; Elbestawi, M.A.; Sokolowski, J.H. High speed face milling of an aluminium silicon alloy casting. CIRP Ann. 2004, 53, 69-72. [CrossRef]

3. Uhlmann, E.; Reimers, W.; Byrne, F.; Klaus, M. Analysis of tool wear and residual stress of CVD diamond coated cemented carbide tools in the machining of aluminum silicon alloys. J. Prod. Eng. 2010, 4, $203-209$. [CrossRef]

4. Polini, R. Chemically vapour deposited diamond coatings on cemented tungsten carbides: Substrate pretreatments, adhesion and cutting performance. Thin Solid Films 2016, 515, 4-13. [CrossRef]

5. Skordaris, G.; Bouzakis, K.-D.; Kotsanis, T.; Boumpakis, A.; Stergioudi, F.; Christofilos, D.; Lemmer, O.; Kölker, W.; Woda, M. Effect of the crystallinity of diamond coatings on cemented carbide inserts on their cutting performance in milling. CIRP Ann. 2019, 68, 65-68. [CrossRef]

6. Bouzakis, E.; Bouzakis, K.-D.; Skordaris, G.; Charalampous, P.; Kombogiannis, S.; Lemmer, O. Fatigue strength of diamond coating-substrate interface assessed by inclined impact tests at ambient and elevated temperatures. Diam. Relat. Mater. 2014, 50,77-85. [CrossRef]

7. Skordaris, G.; Bouzakis, K.-D.; Charalampous, P.; Kotsanis, T.; Bouzakis, E.; Lemmer, O. Effect of structure and residual stresses of diamond coated cemented carbide tools on the film adhesion and developed wear mechanisms in milling. CIRP Ann. 2016, 65, 101-104. [CrossRef]

8. Bouzakis, K.-D.; Skordaris, G.; Bouzakis, E.; Charalampous, P.; Kotsanis, T.; Tasoulas, D.; Kombogiannis, S.; Lemmer, O. Effect of the interface fatigue strength of NCD coated hardmetal inserts on their cutting performance in milling. Diam. Relat. Mater. 2015, 59, 80-89. [CrossRef]

9. Polini, R.; Kumashiro, S.; Jackson, M.J.; Amar, M.; Ahmed, W.; Sein, H. A study of diamond synthesis by hot filament chemical vapor deposition on Nc coatings. J. Mater. Eng. Perform. 2005, 15, 218-222. [CrossRef]

10. Polini, R.; Barletta, M.; Cristofanilli, G. Wear resistance of nano- and micro-crystalline diamond coatings onto WC-Co with Cr/CrN interlayers. Thin Solid Films 2010, 519, 1629-1635. [CrossRef]

11. Silva, S.; Mammana, V.P.; Salvadori, M.C.; Monteiro, O.R.; Brown, L.G. WC-Co cutting tool inserts with diamond coatings. Diam. Relat. Mater. 1999, 8, 1913-1918. [CrossRef]

12. Slack, G.A.; Bartram, S.F. Thermal expansion of some diamondlike crystals. J. Appl. Phys. 1975, 46, 89-98.

13. Woehrl, N.; Hirte, T.; Posth, O.; Buck, V. Investigation of the coefficient of thermal expansion in nanocrystalline diamond films. Diam. Relat. Mater. 2009, 18, 224-228. [CrossRef]

14. Lee, D.G.; Fitz-Gerald, J.M.; Singh, R.K. Novel method for adherent diamond coatings on cemented carbide substrates. Surf. Coat. Technol. 1998, 100-101, 187-191. [CrossRef]

15. Staia, M.H.; D'Alessandria, M.; Quinto, D.T.; Roudet, F.; Marsal Astort, M. High-temperature tribological characterization of commercial TiAlN coatings. J. Phys. Condens. Matter 2006, 18, 1727-1736. [CrossRef] [PubMed]

16. Ferrari, A.C.; Robertson, J. Origin of the $1150-\mathrm{cm}^{-1}$ Raman mode in nanocrystalline diamond. Phys. Rev. B 2001, 63, 121405. [CrossRef]

17. Bouzakis, K.-D.; Michailidis, N.; Hadjiyiannis, S.; Skordaris, G.; Erkens, G. The effect of specimen roughness and indenter tip geometry on the determination accuracy of thin hard coatings stress-strain laws by nanoindentation. Mater. Charact. 2002, 49, 149-156. [CrossRef]

18. Bouzakis, K.-D.; Skordaris, G.; Bouzakis, E.; Makrimallakis, S.; Kombogiannis, S.; Lemmer, O. Fatigue strength of diamond coatings' interface assessed by inclined impact test. Surf. Coat. Technol. 2013, 237, $135-141$. [CrossRef] 
19. Impact-BZ Ltd. Available online: www.impact-bz.com (accessed on 21 August 2020).

20. Teppernegg, T.; Klünsner, T.; Kremsner, C.; Tritremmel, C.; Czettl, C.; Puchegger, S.; Marsoner, S.; Pippan, R.; Ebner, R. High temperature mechanical properties of WC-Co hard metals. Int. J. Refract. Met. Hard Mater. 2016, 56, 139-144. [CrossRef]

21. Skordaris, G. Fatigue strength of diamond coating-substrate interface quantified by a dynamic simulation of the inclined impact test. J. Mater. Eng. Perform. 2014, 23, 3497-3504. [CrossRef] 